\title{
GENETIC CONTROL OF RECOMBINATION IN THE SILKWORM
}

\section{MULTIGENIC CONTROL OF CHROMOSOME 2*}

\author{
JOHN R. G. TURNER† \\ Department of Ecology and Evolution, State University of New York, \\ Stony Brook, N.Y. II794, U.S.A.
}

Received 26.iii.79

\begin{abstract}
SUMMary
Response to selection for particular rates of recombination in the silkworm (Bombyx mori) is rapid; from a highly heterogeneous foundation stock Hasimoto achieved, in only 10 generations, a 32 per cent difference between lines selected for high and low recombination between the dominant markers Striped and Yellow in chromosome 2.

The present study analyses the difference between Hasimoto's high and low stocks by means of a set of four factorial $F_{1}$ crosses, and all but one of the corresponding eight backcrosses. As there is no recombination in females this method can distinguish the effects on recombination of (i) a large inversion in the marked chromosome (chromosome 2), (ii) genes or small inversions in chromosome 2, (iii) genes in the sex chromosome, (iv) genes in the other autosomes, (v) the cytoplasm.

There is no large inversion causing reduced recombination in chromosome 2; the cytoplasm has little, if any effect. A recombination gene (or genes, the analysis does not distinguish) is located in chromosome 2, the high allele being recessive (effect of 6 to 11 per cent). At least one other autosome carries a similar gene, with high recessive (effect of around 8 per cent), and there also appears to be an autosome (or several autosomes) with a low recessive effect of 9 per cent, which may or may not be identical with the other autosome. Further autosomes might be revealed by a more sensitive analysis. There may be a small effect ( $h i g h$ recessive) due to the $\mathrm{X}$ chromosome. There is no overall dominance in the genes controlling recombination. The genes appear to be either of the rec type discovered in Neurospora, or general modifiers of genomic recombination.

Although supergenes in mimetic butterflies at least do not arise by the tightening of linkage between loosely linked or independent loci, modifiers of the type demonstrated in Bombyx may be very effective in tightening still further the linkage within supergenes that come into existence by the alternative "sieve" mechanism.

If most modifiers of recombination are general in their action, rather than specific to one short length of chromosome, then this may in part explain why the genome does not congeal.
\end{abstract}

\section{InTRODUCTION}

Genetrc control of recombination or of chiasma frequency has been shown in Schistocerca, Tribolium, mice and Lima beans (Allard, 1963; Shaw, 1972;

* Contribution number 318 from the Program in Ecology and Evolution of the State University of New York at Stony Brook.

$\dagger$ Present address: Department of Genetics, University of Leeds, Leeds LS2 9JT, England. 
Dewees, 1975; de Boer and van der Hoeven, 1977), and recombination in Drosophila has been altered by selection in one or both directions (Parsons, 1958; Chinnici, 1971a; Kidwell, 1972a, b; Abdullah and Charlesworth, 1974); only Acton (1961) reported entirely negative results. The genetics of recombination has been throughly investigated in fungi (Catcheside, 1977). Despite this, there have been few attempts, except those of Chinnici (1971 $b$ ) and Kidwell $(1972 a, b)$, to investigate the genetic basis of recombination control in a multicellular organism. The present study aims to find the genes responsible for the difference in recombination fraction between the high and low recombination lines of the silkworm originally selected by Hasimoto (1960), and maintained since by the stock centres in Tokyo and Fukuoka (see Chikushi, 1972). The experiment uses a new factorial design which removes the need for chromosome substitution.

Fisher (1930) was the first to point out that if the genes at two loci interact in their effects on some adaptive character, then natural selection will favour tighter linkage between them. This theory has been used to explain "supergenes", clusters of very tightly linked, functionally independent loci, controlling related characters, such as those concerned with heterostyly in primroses or camouflage in snails (e.g. Sheppard, 1975). They have been extensively investigated in mimetic butterflies; for example in Papilio memnon, Clarke and Sheppard (1971, 1977) identified six loci controlling elements of the mimetic pattern, all within a map length of less than 0.006 , and were able to determine the order as tails, blue hindwing marks, white hindwing marks, forewing colour, epaulet colour, abdomen colour. But another outcome of Fisher's theory, as he himself realised, is that ultimately all recombination should cease or the genome should "congeal "; several theoretical studies have been devoted to finding the force which prevents this (see Maynard Smith, 1977).

Were recombination not under genetic control, then the theory that supergenes form by the tightening of linkage would be void, and the question "Why does the genome not congeal?" would be readily answered. As the lepidoptera figure so largely in discussions of supergenes, it is of great interest to know how readily recombination may be altered in this group. Hasimoto (1960) investigated this question in the silkmoth, Bombyx mori. He prepared a highly heterozygous stock of silkworms by hybridising 11 existing stocks and then, using the dominant linked markers Striped $\left(p^{S}\right)$ and Yellow $(Y)$ (like most known markers in this species, manifesting themselves in the larvae), selected for increased and reduced recombination in a long segment of the second chromosome. He succeeded in altering the high line to a modal crossover rate of between 37 per cent and 39 per cent in 10 generations, and the low line to a mode of 5 per cent to 7 per cent in less than 10 generations (Hasimoto, 1960). This difference of over 30 per cent represents a much stronger and faster response than has been obtained in Drosophila. The crossover rates thereafter remained stable despite continued selection for three or four generations. A previous apparently unpublished experiment by Kogure had achieved high and low values of 24 per cent and 12 per cent. The $F_{1}$ between Hasimoto's high and low lines had a crossover rate of 20 per cent (roughly the mean of the two lines) with a low variance; the backcrosses to the parental stocks showed a high variance. Unfortunately, although this work pre-dates almost all the successful work on other species it has remained virtually unknown to western geneticists. 


\section{BREEDING PLAN}

The markers used by Hasimoto (and in the present experiments) are:

Striped: a dominant allele at the $p$ locus, mapping at 0.0 on chromosome 2. From the third instar onward it gives the larva a handsome pattern of black and white stripes; the wild-type larva is white with a few black markings. The standard symbol for the striped allele is $p^{S}$. The alternate "normal " allele at this locus, producing a wild-type white larva with a few small black marks, will be designated + for the purposes of this paper. (The standard names of the " normal " alleles are $p^{3}$ in the high stock and $p$ in the low.)

Yellow: a dominant allele $(\mathcal{Y})$ whose standard map position, determined by Tanaka in 1913 (cited by Chikushi, l.c.), by recombination with Striped and with the Moricaud allele at the $p$ locus, is 25.6 ; it produces yellow haemolymph and a yellow cocoon, or in a minority of individuals a pale strawcoloured cocoon. The wild-type allele $(+)$ produces colourless haemolymph and a white coccon. Haemolymph colour is easily scored from the third instar onward by looking at the prolegs against bright daylight. Details and illustrations are given by Chikushi (1972).

The factors causing the considerable difference in recombination between the high and low stocks were to be located in the genome by a process of elimination. The pure high and low stocks are propagated with heterozygous second chromosomes by mating $p^{S} Y /++$ males with $++1++$ females in every generation. Thus they each contain two genotypes. This permits four reciprocal $\mathrm{F}_{1}$ (high $\times$ low) crosses, designated $\mathrm{A}, \mathrm{B}, \mathrm{C}, \mathrm{D}$, with different arrangements of mutant and wild type male and female parents; their makeup is shown in table 1 . The recombination fraction of the

TABLE 1

The four reciprocal $F_{1}$ crosses

$\begin{array}{cll}\text { Type } & \text { Female parent } & \text { Male parent } \\ \text { A } & p^{s} /++ \text { high } & ++/++ \text { low } \\ \text { B } & p^{s} /++ \text { low } & ++/++ \text { high } \\ \text { C } & ++/++ \text { high } & p^{s} /++ \text { low } \\ \text { D } & ++/++ \text { low } & p^{S} / /+ \text { high }\end{array}$

$p^{S} Y /++$ males in the $\mathrm{F}_{1}$ can then be estimated by mating them with wild type females and scoring the offspring. The genotypes of these males in each of the four reciprocal crosses are shown in table 2 . It can be seen that $A$ and $C$ differ from $B$ and $D$ only in their cytoplasm (designated $C$ ), and that $\mathrm{A}$ and $\mathrm{D}$ differ from $\mathrm{B}$ and $\mathrm{C}$ only in having high $p^{S} \Upsilon$ and low ++ against low $p^{S} \Upsilon$ and high ++ second chromosomes. Thus an analysis of variance (on the recombination fractions) of the type

Columns

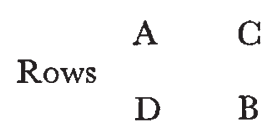

will detect a cytoplasmic gene by a significant sum of squares between the rows, and by a significant sum of squares between the columns, a factor that 
is closely linked to the $p-\Upsilon$ segment of the second chromosome. This might be an inversion containing all or part of the segment, or a gene in strong gametic disequilibrium with the segment; for short, it is referred to as an "inversion" in chromosome 2 throughout this paper.

Table 2

Genotypes of male $F_{1}$ offspring and backcross offspring

\begin{tabular}{|c|c|c|c|}
\hline $\begin{array}{l}\text { Mating } \\
\text { type }\end{array}$ & $F_{1}$ & $\begin{array}{l}\text { Backcross } \\
\text { to high }\end{array}$ & $\begin{array}{c}\text { Backcross } \\
\text { to low }\end{array}$ \\
\hline A & $\begin{array}{l}\mathbf{p}^{\mathrm{s}} \mathbf{X} \mathbf{R} \\
++\mathrm{X} \mathbf{R}\end{array}$ & $\begin{array}{l}\mathbf{p}^{\mathrm{SY}} \mathrm{X} R \mathbf{G} \\
++\mathbf{X} \mathbf{R}\end{array}$ & $\begin{array}{c}\mathbf{p}^{\mathrm{SY}} \mathrm{X} R \mathbf{G} \\
++\mathrm{XR}\end{array}$ \\
\hline B & $\begin{array}{l}\mathrm{p}^{\mathrm{SY}} \times \mathrm{R} \mathrm{C} \\
++\mathrm{X} \mathrm{R}\end{array}$ & $\begin{array}{l}\mathrm{p}^{\mathrm{SY}} \mathbf{X} R \mathrm{C} \\
++\mathbf{X} \mathbf{R}\end{array}$ & $\begin{array}{l}\mathrm{p}^{\mathrm{SY}} \mathrm{X} R \mathrm{C} \\
++\mathrm{XR}\end{array}$ \\
\hline $\mathrm{G}$ & $\begin{array}{l}++\mathbf{X} \text { R G } \\
\mathrm{p}^{\mathrm{SY}} \text { X R }\end{array}$ & $\begin{array}{l}\mathrm{p}^{\mathrm{SY}} \mathbf{X} R \mathbf{C} \\
+\mathbf{+} \mathbf{X}\end{array}$ & $\begin{array}{l}\mathrm{p}^{\mathrm{SY}} \mathrm{X} R \mathbf{C} \\
++\mathrm{X} \mathrm{R}\end{array}$ \\
\hline $\mathrm{D}$ & $\begin{array}{l}++ \text { X R C } \\
\mathbf{p}^{S \mathbf{Y} X \mathbf{R}}\end{array}$ & $\begin{array}{l}\mathbf{p}^{\mathrm{SY}} \mathbf{X} R \mathrm{C} \\
++\mathbf{X} \mathbf{R}\end{array}$ & $\begin{array}{l}\mathbf{p}^{\mathrm{SY}} \mathbf{X} R \mathrm{C} \\
++\mathrm{XR}\end{array}$ \\
\hline \multicolumn{4}{|c|}{$\begin{array}{l}\text { psY-mutant second chromosome; }++- \text { wild-type } \\
\text { second chromosome; X-male-determining sex-chromos- } \\
\text { some; R-remaining autosomes; C-cytoplasm; Bold } \\
\text { type-from high line; Roman-from low line; Italic- } \\
\text { mixture of high and low chromosomes. Female parental } \\
\text { contribution above, male below. }\end{array}$} \\
\hline
\end{tabular}

The $p^{S} Y /++$ females of the $\mathrm{F}_{1}$ are backcrossed to wild-type males of the high and of the low stocks, producing the eight types of backcross whose genotypes are tabulated in table 2 . The absence of recombination in the females ensures that each high and low chromosome is transmitted intact to their male offspring, who are then tested by mating them to wild-type females. Within the backcrosses to each line, an analysis of variance, as in (1), on the recombination fractions of these males will detect between rows, either a cytoplasmic gene or a gene carried in the sex chromosome (designated $\mathrm{X}$ in this paper, males being homogametic), and between columns, a gene in chromosome 2 which is not in disequilibrium with the $p$ - $\Upsilon$ segment (referred to as a "gene" in chromosome 2). A cytoplasmic gene can be distinguished from an X-linked gene in that the former would make the mean of $A$ and $C$ exceed that of $B$ and D, while the effect would be reversed for an $\mathrm{X}$-linked gene. The mutual cancellation of effect that could result if both were present could be detected because cytoplasmic genes are detected unconfounded with any other factor in the $\mathrm{F}_{1}$. The backcross to the high line will detect chromosomal genes for low recombination which are not recessive; the backcross to the low line will detect chromosomal genes for high recombination which are not recessive.

The genes discovered by the three analyses are listed in table 3. A significant interaction between the two factors might indicate a real physiological interaction. On the other hand $A$ and $B$ differ from $C$ and $D$ in that the former pair receive their $p^{s} r$ chromosome from a female in the high or low stock, the latter pair receiving this chromosome from a male in one or other of the original stocks (and reciprocally for the ++ chromosome). 
TABLE 3

Genetic differences detected by two-way ANOVA on $F_{1}$ and backcrosses

\begin{tabular}{cll} 
& \multicolumn{1}{c}{ Columns } & \multicolumn{1}{c}{ Rows } \\
$\mathrm{F}_{1}$ & "Inversion " in chromosome 2 & Cytoplasm \\
s to high "Gene "* in chromosome 2 & Cytoplasm/X chromosome $\dagger$ \\
ss to low "Gene "* in chromosome 2 & Cytoplasm/X chromosome $\dagger$
\end{tabular}

* With reversed dominance in the two backcrosses.

$\dagger$ With reversed dominance or different $\mathrm{X}$ chromosome $\times$ cytoplasm interactions in the two backcrosses.

The only obvious difference between these classes is therefore the presence or absence of recombination throughout the genome; thus a significant interaction might indicate the effects of recombination in breaking up a linked block of genes that was controlling recombination, or in separating an " inversion" from the $p-\Upsilon$ segment of chromosome 2.

The three analyses can thus be used to detect or eliminate the effects of the cytoplasm, the $\mathrm{X}$ chromosome, and chromosome 2 on recombination between $p^{S}$ and $Y$ in chromosome 2. The effects of genes in the remaining autosomes can be detected by segregation within the backcrosses and within an $\mathrm{F}_{2}$ generation produced by sib-mating members of the $F_{1}$. From table 2 it can be seen that whereas each chromosome in a backcross individual has been transmitted intact through its female $F_{1}$ parent, the chromosomes themselves have undergone chromosome segregation, so that each backcross male carries a mixture of high and low autosomes in the maternal part of his genome (the paternal part being pure high or pure low according to the backcross). Segregation between these males can therefore detect the number of autosomes involved, and differences in the pattern of segregation between the high and low backcrosses will indicate differences in the dominance.

The procedure has been described as an analysis of variance, as that is the easiest and most familiar way to conceive it. In practice unavoidable differences in the size of each brood, and fortuitous differences in the number of males of each type available for testing, produce a markedly non-homogeneous error variance for the recombination fraction, and considerable inequalities between cells in the analysis. Therefore a more naïve statistical test has been devised. For any group of $k$ broods, one can compute the value of $\chi^{2}$ for a $2 \times k$ table, entering the total parental and recombinant offspring for each brood in each column. One can thus test, say, all $\mathrm{F}_{1}$ broods of type A. Significant heterogeneity within such a group, as shown by $\chi_{A}^{2}$, will indicate that there is a greater variance between broods in the recombination fraction than is accounted for by sampling errors in broods of this size. Likewise, one can compute a value, say $\chi_{A C}^{2}$, for two types of $\mathrm{F}_{1}$ combined into a single $2 \times\left(k_{A}+k_{C}\right)$ table. The heterogeneity $\chi^{2}$ found from $\chi_{A C}^{2}-\left(\chi_{A}^{2}+\chi_{C}^{2}\right)$ tests for differences in the distribution of recombination fractions between $F_{1}$ broods of type $A$ and of type $\mathrm{C}$. Similarly, subtracting such combined $\chi^{2}$ values from the total $\chi^{2}$ for the $\mathrm{F}_{1}$, that is $\chi_{A B C D}^{2}-\left(\chi_{A C}^{2}+\chi_{B D}^{2}\right)$, gives a test analogous to the " rows " effect in a two-way analysis of variance, and similarly $\chi_{A B C D}^{2}-\left(\chi_{A D}^{2}+\chi_{B C}^{2}\right)$ is analogous to "columns". The interaction can be examined by $\chi_{A B C D}^{2}-\left(\chi_{A B}^{2}+\chi_{C D}^{2}\right)$.

This method of analysis is unfortunately not truly orthogonal, and cases 
on the borderline of significance (which are few in this study) must be treated with caution.

\section{Methods}

Pure high and low stocks (catalogue numbers r22 and r21-see Chikushi, 1972) were received as eggs at intervals by airmail or air freight from the Faculty of Agriculture of Kyushu University at Fukuoka.

Techniques for rearing were adapted from those for commercial silkfarming used in Japan (Ayuzawa et. al., 1972). Diapausing eggs, kept for periods of 2 months at $5^{\circ} \mathrm{C}$ and then $2.5^{\circ} \mathrm{C}$ (after being brought down gradually from room temperature), were raised to room temperature in the spring, producing almost synchronous hatching 1 or 2 weeks later. Larvae were kept at densities of 100 to 200 in covered containers in a constant temperature chamber set at $25^{\circ} \mathrm{C}$ and 70 per cent relative humidity, and fed on finely chopped leaves of the White and the Red Mulberry (Morus alba and $M$. rubra). Feed was changed and the container kept clean by laying the chopped leaves on an oblong of butter muslin (cheesecloth in U.S.A.) placed on top of the larvae, who pushed their way through the cloth on smelling the fresh food.

Those larvae which were to breed were allowed to spin their cocoons in the container, often in old egg-trays. The cocoons were then removed and each isolated in an individual paper cup covered with muslin secured with a rubber band. Females were normally mated within 24 hours of eclosion, but males were sometimes stored at $16^{\circ} \mathrm{C}$ for up to a week before mating. Moths were mated by placing a male and a female together on a $4 \times 6$ inch catalogue card on a laboratory bench. Three hours after copulation the pair were forcibly pulled apart, the male replaced in his cup and the female left beneath an inverted cup on the card. The card with its eggs was easily stored, handled and labelled.

Diapause was controlled by varying the day length: females which were required to lay diapausing eggs were subjected to continuous light when they themselves were late embryos within the eggshell; those which were required to lay non-diapausing eggs were given day lengths of less than 10 hours.

Larvae were scored and then killed when at least $2 \mathrm{~cm}$ long, usually at about $2.5 \mathrm{~cm}$, when the characters were easily visible and before they were consuming excessive amounts of food. As the characters cannot be scored in the moths, in breeding stocks the two parental types were at this stage separated into different boxes and only the recombinants killed. At this size a few of the slower growing larvae in a brood may still be sufficiently undersized for their colour to be ambiguous. Scoring errors from this cause have been few, as doubtful larvae have normally been kept for a few more days and then rescored. Errors in diagnosing the skin colour become very obvious in large larvae (one such error was found), and errors in diagnosing blood colour would become obvious when the cocoon was spun (no such errors were found).

Bombyx mori are at all times extremely immobile; unfed larvae do not wander, female moths move hardly at all, and males do not (except in very rare instances) fly, or separate unassisted from their mate. Newly hatched larvae if unfed will walk a matter of inches before dying of starvation, but 
the distance traversed is very small unless the humidity is high. Risks of contamination are therefore minimal. In one generation we kept most of our egg cards a few inches apart on a bench in a rather dry laboratory because of a temporary shortage of boxes; frequent checking and the extraordinarily slow movement of the larvae (no more that 4 inches in 12 hours at this humidity) ensured that there was no contamination, and hatching was confined to a few hours in the morning after the laboratory lights were switched on. We found one labelling error in another generation: a male alleged to be $p^{S} Y /++$ gave an all wild-type brood. One brood (in the B to high backcross) became contaminated by a wandering female known to be wild type mated to wild type. This brood has been treated as having the same number of ++ individuals as $p^{S} Y$ individuals; the statistical bias so introduced is very slight. Another (in the $B$ to low backcross) turned out to have had a mother who was $p^{S Y} /++$ instead of $++1++$. The recombination fraction of the male parent is included in the histograms and unweighted means, but excluded from weighted means and $\chi^{2}$ analyses.

\section{Results}

(i) No crossing-over in females

The experimental design requires that chromosomes be transmitted intact in the female parents of the backcrosses. Our broods confirm the fact, first noted by Sturtevant (1915), that there is no recombination in females, at least for the second chromosome (and so presumably for the rest of the genome); they also show that there is no significant level of contamination in our broods. No crossovers have appeared among 3466 offspring of 44 doubly heterozygous females.

\section{(ii) Regular segregation}

All 213 backcross sibships (excluding the contaminated one) and 11 similar sibships of unrecorded ancestry (not otherwise analysed), have been subjected to $\chi^{2}$ tests for $1: 1$ segregation at the $p$ and $Y$ loci; to these 48 tests have been added 44 tests from the doubly heterozygous females. In the total of 492 tests, 28 have probabilities that are too low at the 5 per cent level, 430 are a satisfactory fit, and after applying Yates' continuity correction 28 exceed the 5 per cent level for a poor fit, and a further six exceed the 1 per cent level. (Roughly half of the poor fits show an excess of mutants, and roughly half of wild types.) As these numbers are a good fit to the expected 5:90:4:1 ratio $\left(\chi_{3}^{2}=4 \cdot 6, \mathrm{P}=0 \cdot 2\right)$, it appears that there is no departure other than random from the expected segregations at the two loci (which share the significant departures roughly equally), and that the genes do not affect viability to any detectable extent. The estimation of recombination fractions is therefore straightforward.

\section{(iii) Polygenic inheritance of recombination rates}

The overall rates of recombination in males of the high and low stocks and of the $F_{1}, F_{2}$ and backcross broods are displayed in fig. 1 and in table 4 . 


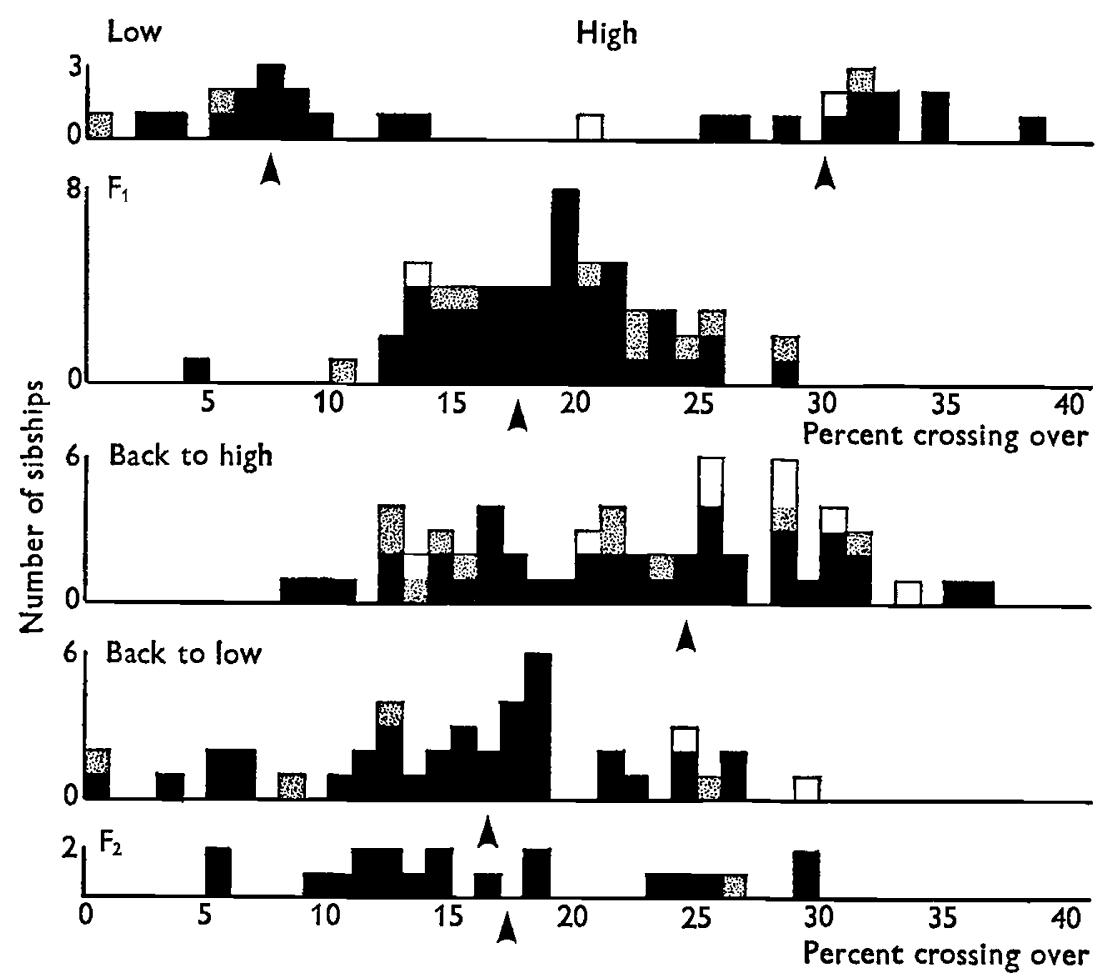

Fig. 1.-Distribution of recombination fractions in males of the high and low stocks and their hybrids. Shading indicates a standard error of the untransformed recombination fraction in excess of 0.05 ; broods with standard errors greater than 0.07 are white; no brood is included with fewer than 10 offspring in this or any of the other figures. Arrows are weighted means.

The weighted mean recombination rate is simply the number of recombinants out of the total offspring for that type of cross; the unweighted mean takes all the sibships in that cross (excluding those with fewer than 20 individuals) and averages them. Even with this exclusion, differences in sibship size are no doubt introducing an error variance that differs from cross to cross, making the standard deviation of the recombination rate unreliable; the statistic $\chi / \sqrt{ } \mathrm{N}$ (using $\chi^{2}$ from the $2 \times k$ contingency table where $\mathrm{N}$ is the total number of offspring scored) has been used as an alternative measure of the standard deviation. In fig. 1, a standard error of over 0.05 causes a sibship to be shaded, and of over 0.07 to be left white; one can thus obtain a subjective notion of the reliability of the histograms. The difference between weighted and unweighted means is never more than $1 \frac{1}{2}$ per cent.

With one exception, the crosses show the characteristic features of polygenic inheritance and high homozygosity of the parental stocks.

The recombination rate of the high stock (Kyushu number r22) is 31 per cent and that of the low (Kyushu number r21) is 7 per cent; both have a rather low between-male variance, and neither gives any sign of the strong bimodality which would result from the stock being heterozygous for an 
TABLE 4

Mean and standard deviation (as $\chi / \sqrt{ } N$ ) of recombination in males of the high and low stocks and their hybrids

\begin{tabular}{|c|c|c|c|c|c|c|c|c|}
\hline \multirow[b]{2}{*}{ Generation } & \multirow{2}{*}{$\begin{array}{c}\text { No. of } \\
\text { males } \\
\text { tested } \\
(k)^{*}\end{array}$} & \multirow{2}{*}{$\begin{array}{l}\text { No. of } \\
\text { offspring } \\
\text { scored } \\
\text { (N) }\end{array}$} & \multirow{2}{*}{$\begin{array}{l}\text { No. of } \\
\text { recombi- } \\
\text { nants }\end{array}$} & \multicolumn{2}{|c|}{ Recombination rate } & \multirow[b]{2}{*}{$\chi^{2}$} & \multirow[b]{2}{*}{$\mathbf{P}$} & \multirow[b]{2}{*}{$\chi / \sqrt{ } \mathrm{N}$} \\
\hline & & & & Weighted & $\begin{array}{l}\text { Un- } \\
\text { weighted } \dagger\end{array}$ & & & \\
\hline High stock & 14 & 1920 & 589 & 0.307 & 0.307 & $8 \cdot 82$ & 0.79 & 0.07 \\
\hline Low stock & 15 & 2136 & 155 & $0 \cdot 072$ & 0.067 & $17 \cdot 76$ & $0 \cdot 22$ & 0.09 \\
\hline $\mathrm{F}_{1}$ & 60 & 6943 & 1268 & $0 \cdot 183$ & $0 \cdot 187$ & $67 \cdot 66$ & $0 \cdot 21$ & $0 \cdot 10$ \\
\hline Back to high & $63+$ & 6528 & 1603 & $0 \cdot 246$ & $0.232 \div$ & 153.52 & $O\left(10^{-9}\right)$ & $0 \cdot 15$ \\
\hline Back to low & 42 & 5087 & 857 & $0 \cdot 168$ & $0 \cdot 159 \S$ & $122 \cdot 46$ & $O\left(10^{-9}\right)$ & $0 \cdot 15$ \\
\hline $\mathrm{F}_{2}$ & 20 & 2492 & 428 & $0 \cdot 172$ & $0 \cdot 167$ & $87 \cdot 09$ & $<10^{-\theta}$ & $0 \cdot 19$ \\
\hline
\end{tabular}

* In this and the other tables, males with fewer than 10 offspring are omitted from this and other counts, although their offspring have been included in the weighted means. $\chi^{2}$ has $(k-1)$ degrees of freedom, one less than the number $(k)$ of males, for a $2 \times k$ table.

$\dagger$ Excluding sibships with fewer than 20 individuals.

\$ See notes to table 9 .

$\S$ See notes to table 7.

$\mathrm{O}\left(10^{-9}\right)=$ of the order of $10^{-9}$.

inversion. It should go without saying that a $\chi^{2}$ heterogeneity test between the high and low stocks is highly significant.

The low stock still has a recombination value roughly the same as that reported by Hasimoto ( 5 per cent to 7 per cent against 7 per cent in the present experiment); the high stock has dropped to 31 per cent from the value of 37 per cent to 39 per cent achieved by Hasimoto, probably as a result of relaxed selection, or of reverse selection because of propagation of the stock from non-recombinant parents.

The mean rate of recombination in the $F_{1}$, at 18 per cent, is almost exactly the average of the two parental stocks (19 per cent); there is no overall directional dominance in the control of recombination. Hasimoto's $\mathrm{F}_{1}$ had an almost identical mean value of 20 percent (Hasimoto, 1960). The variances of the parental stocks and of the $F_{1}$ are all closely similar, and the probability values for the $2 \times k$ tables give no indication of any real genetic heterogeneity within any of the three crosses: that is, all the variation exhibited in fig. 1 can be accounted for by the error variance inherent in taking sibships of the sizes actually obtained.

The $\mathrm{F}_{2}$ maintains almost the same mean (17 per cent) but has a greatly enhanced variance; the much wider spread of the $\mathrm{F}_{2}$ seen in fig. 1 is highly significant statistically, and the value of $87 \cdot 1$ for $\chi_{19}^{2}$ shows that this distribution has an utterly negligible chance of being drawn by sampling error from a single population. There is undoubtedly segregation between $F_{2}$ males for genes controlling recombination. The same is true of both backcrosses. The standard deviation of the $F_{2}$ is about double that of the $F_{1}$ (table 4 ), and this increase also is highly significant $\left(\chi_{1}^{2}=436\right)$.

The backcross to the high stock follows this orthodox pattern: a variance intermediate between the $F_{1}$ and the $F_{2}$, and a mean ( 25 per cent) at the midpoint (24 per cent) of the high stock and the $F_{1}$, showing again no directional dominance. The backcross to the low stock is something of an oddity: its variance is roughly that of the high backcross, but its mean, instead of the expected midpoint (just under 13 per cent) of the $F_{1}$ and low stock is, at over 16 per cent, only around 1 per cent under that of the $F_{1}$. 
Given the high variances this could be a chance effect. However, the histogram (fig. 1) does show a quite marked bimodality in the low backcross, and cutting the distribution at the antimode (19 per cent) shows that the higher mode very nearly accounts for the discrepancy: the mean of the lower mode is 14 per cent.

Apart from this discrepancy, the crosses, based upon scoring nearly 25,300 offspring from 213 males, show rather clearly that recombination is under multigenic control with no directional dominance. In this they resemble the findings of Chinnici $(1971 a, b)$, but not of Kidwell $(1972 a, b)$ or Dewees (1975) who found overall dominance of low recombination.

\section{(iv) Location of the recombination control genes}

(a) Inversion and cytoplasm. Even with the numbers scored, the location of the genes is rather less certain: one of the 12 types of cross ( $\mathrm{C}$ to low) has not been obtained, and some of the others are represented by fewer males than is wholly convenient. However, with appropriate caution, and pending the breeding of further crosses, some conclusions may be drawn.

As can be seen from table 5 and fig. 2, there is some variation between the different types of $F_{1}$, produced chiefly by type $D$ having a mean 4 or 5 per cent below $B$ and $C$. In the analysis of $\chi^{2}$ this gives a significant effect attributable to an "inversion" in chromosome 2, and a similar but only just significant effect (one-tailed) due to the cytoplasm (table 6). But it is clear from the distributions (fig. 2) that there is no large inversion tying up

TABle 5

The $F_{1}$ : recombination rates in males

\begin{tabular}{|c|c|c|c|c|c|c|c|c|}
\hline \multirow[b]{2}{*}{$\begin{array}{l}\text { Type of } \\
\text { cross }\end{array}$} & \multirow[b]{2}{*}{$\begin{array}{l}\text { No. of } \\
\text { crosses }\end{array}$} & \multirow{2}{*}{$\begin{array}{c}\text { No. of } \\
\text { males } \\
\text { tested }(k)\end{array}$} & \multirow{2}{*}{$\begin{array}{l}\text { No. of } \\
\text { offspring } \\
\text { scored }\end{array}$} & \multirow{2}{*}{$\begin{array}{l}\text { No. of } \\
\text { recombi- } \\
\text { nants }\end{array}$} & \multicolumn{2}{|c|}{ Recombination rate } & \multirow[b]{2}{*}{$\chi^{2}$} & \multirow[b]{2}{*}{$\mathbf{P}$} \\
\hline & & & & & Weighted & $\begin{array}{c}\text { Un- } \\
\text { weighted }\end{array}$ & & \\
\hline A & 2 & 14 & 1308 & 244 & $0 \cdot 187$ & $0 \cdot 189$ & 10.95 & 0.62 \\
\hline B & 2 & 9 & 1171 & 22 & $0 \cdot 195$ & 0.204 & 10.08 & 0.26 \\
\hline C & 3 & 24 & 2928 & 582 & $0 \cdot 199$ & 0.198 & $25 \cdot 75$ & 0.31 \\
\hline $\mathrm{D}$ & 3 & 13 & 1536 & 214 & 0.139 & $0 \cdot 153$ & 12.47 & 0.41 \\
\hline All $F_{1}$ & 10 & 60 & 6943 & 1268 & $0 \cdot 183$ & $0 \cdot 187$ & $67 \cdot 66$ & 0.21 \\
\hline
\end{tabular}

Offspring of $\mathrm{F}_{1} p^{s} x /++$ males mated to homozygous wild-type females. See notes below table 4 .

TABle 6

Analysis of $\chi^{2}$ for the $F_{1}$

\begin{tabular}{|c|c|c|c|c|c|c|}
\hline \multirow{2}{*}{$\begin{array}{l}\text { Broods } \\
\text { combined }\end{array}$} & \multicolumn{2}{|c|}{ Overall } & \multicolumn{4}{|c|}{ Residual heterogeneity } \\
\hline & $\chi^{2}$ & $\mathrm{df}$ & Broods subtracted* & $\chi_{1}^{2}$ & $\mathbf{P}$ & Source \\
\hline$A+C$ & 37.57 & 37 & $\mathrm{~A}$ and $\mathrm{C}$ & 0.88 & $0 \cdot 35$ & - \\
\hline$B+D$ & $27 \cdot 02$ & 21 & $\mathrm{~B}$ and $\mathrm{D}$ & $4 \cdot 47$ & 0.03 & - \\
\hline$A+D$ & $26 \cdot 09$ & 26 & $A$ and $D$ & $2 \cdot 68$ & $0 \cdot 10$ & - \\
\hline $\mathrm{B}+\mathrm{C}$ & 35.92 & 32 & $\mathrm{~B}$ and $\mathrm{C}$ & 0.09 & $0 \cdot 76$ & - \\
\hline$A+B+C+D$ & $67 \cdot 57$ & 59 & $(A+C)$ and $(B+D)$ & $2 \cdot 91$ & $0.04 \uparrow$ & Cytoplasm \\
\hline$A+B+C+D$ & $67 \cdot 57$ & 59 & $(A+D)$ and $(B+C)$ & $5 \cdot 56$ & 0.02 & Inversion \\
\hline$A+B+C+D$ & 67.57 & 59 & $(A+B)$ and $(C+D)$ & 0.05 & 0.83 & Interaction \\
\hline
\end{tabular}

* Values of $\chi^{2}$ and df $(=k-1)$ for single classes of broods are in table 5 .

$\uparrow$ One-tailed; others two-tailed. 
the marker loci in chromosome 2, for this would produce strong bimodality with one mode at zero. What could be lowering the means of $\mathrm{A}$ and $\mathrm{D}$ is a gene in chromosome 2 in slight gametic disequilibrium with the marked segment, or a small inversion inside the marked segment but not including the marker loci. On balance though, it seems more likely that there is some genetic heterogeneity within one or both of the parental stocks, and that this has caused a fortuitous depression in the mean of the type $\mathrm{DF}_{\mathbf{1}}$. It must be remembered that none of the heterogeneity between the types of $F_{1}$ is sufficient to give the overall distribution a variance greater than would be obtained by sampling error and that the $\chi^{2}$ analysis is not entirely reliable.

As the effect only just reaches formal significance, there is even less ground for believing that the cytoplasm influences recombination. Its effect cannot be more than 4 or 5 per cent at the most.

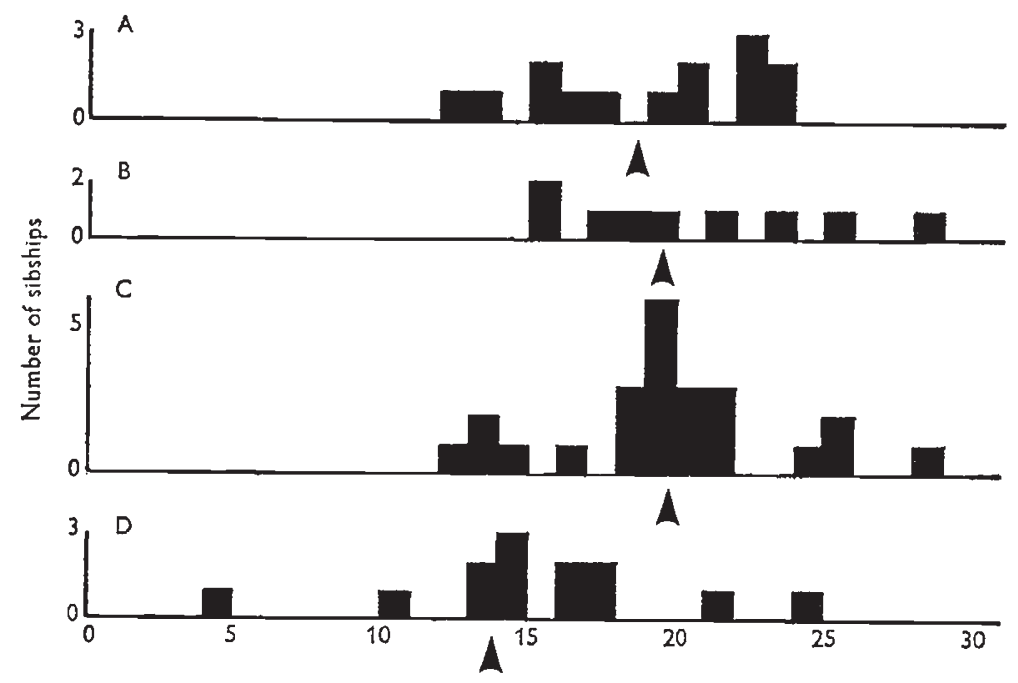

Fig. 2.-Distribution of recombination fractions in the four types of $F_{1}$. There are no extremely low recombination fractions such as might be produced by heterozygosity for a large inversion. Arrows are weighted means.

All this is very similar to the findings of Kidwell (1972a), who noted a few per cent difference between her reciprocal $F_{1}$ crosses in Drosophila, which must have been due either to the cytoplasm, as she suggested, or to a gene with a small amount of disequilibrium with the marked segment (a visible inversion was excluded microscopically).

(b) Chromosome 2 and sex chromosome. A significant difference between the "rows" in the backcrosses indicates the action of the $\mathrm{X}$ chromosome (provided the cytoplasm is excluded) and between the "columns", the effect of the marked, selected chromosome (chromosome 2) itself (table 3). There is no indication that either of these chromosomes affects recombination in the backcrosses to the low stock (table 7); although the high variances within each type of backcross clearly indicate the segregation of several chromosomes affecting recombination, the analysis of $\chi^{2}$ (table 8) shows no detectable differences between the distributions of any of the three types of backcross obtained. Thus the absence of the type $\mathrm{C}$ backcross does not raise 
TABle 7

The backcross to the low stock: recombination rates in males

\begin{tabular}{|c|c|c|c|c|c|c|c|c|}
\hline \multirow[b]{2}{*}{$\begin{array}{c}\text { Type of } \\
\text { cross }\end{array}$} & \multirow[b]{2}{*}{$\begin{array}{l}\text { No. of } \\
\text { back- } \\
\text { crosses }\end{array}$} & \multirow[b]{2}{*}{$\begin{array}{c}\text { No. of } \\
\text { males } \\
\text { tested }(k)\end{array}$} & \multirow[b]{2}{*}{$\begin{array}{l}\text { No. of } \\
\text { offspring } \\
\text { scored }\end{array}$} & \multirow[b]{2}{*}{$\begin{array}{l}\text { No. of } \\
\text { recombi- } \\
\text { nants }\end{array}$} & \multicolumn{2}{|c|}{ Recombination rate } & \multirow[b]{2}{*}{$x^{2}$} & \multirow[b]{2}{*}{$\mathrm{P}$} \\
\hline & & & & & Weighted & $\begin{array}{c}\text { Un- } \\
\text { weighted }\end{array}$ & & \\
\hline $\mathrm{A}$ & 2 & 9 & 1135 & 202 & $0 \cdot 178$ & $0 \cdot 186$ & $12 \cdot 82$ & $0 \cdot 12$ \\
\hline B & 3 & 7 & 945 & 14 & $0 \cdot 156$ & $0 \cdot 1$ & 25.93 & $0 \cdot 0002$ \\
\hline D & 6 & 26 & 3007 & 507 & $0 \cdot 169$ & $0 \cdot 154^{*}$ & $82 \cdot 88$ & $3 \times 10^{-8}$ \\
\hline Total & 11 & 42 & 5087 & 857 & $0 \cdot 168$ & $0 \cdot 159$ & $122 \cdot 46$ & $\mathrm{O}\left(10^{-9}\right)$ \\
\hline
\end{tabular}

Offspring of $p^{S} r /++$ males mated to homozygous wild-type females (the males derived from $p^{s} r /++$ females of the $F_{1}$ crossed with wild-type males of the low stock).

* Includes the brood described on p. 279, which is excluded from all other statistics.

TABLE 8

Analysis of $\chi^{2}$ for the backcross to the low stock

\begin{tabular}{|c|c|c|c|c|c|c|c|}
\hline \multirow{2}{*}{$\begin{array}{l}\text { Broods } \\
\text { combined }\end{array}$} & \multicolumn{2}{|c|}{ Overall } & \multicolumn{4}{|c|}{ Residual heterogeneity } & \multirow[b]{2}{*}{ Source } \\
\hline & $\chi^{2}$ & $\mathrm{df}$ & subtracted* & $\chi^{2}$ & $\mathrm{~d} \mathbf{f}$ & $\mathbf{P}$ & \\
\hline$B+D$ & $109 \cdot 54$ & 32 & $B$ and $D$ & $0.73 \dagger$ & 1 & $0 \cdot 30$ & $\mathrm{X}$ chromosome \\
\hline$A+D$ & $95 \cdot 62$ & 34 & $A$ and D & $-0 \cdot 08^{+}$ & i & $1 \cdot 00$ & Chromosome 2 \\
\hline$A+B$ & $39 \cdot 56$ & 15 & $A$ and $B$ & 0.80 & 1 & 0.37 & Interaction \\
\hline$A+B+D$ & $122 \cdot 46$ & 41 & $A, B$ and $D$ & $0 \cdot 82$ & 2 & $0 \cdot 34$ & - \\
\hline
\end{tabular}

any serious problems of interpretation, as it would have done had any differences been detected; it is hoped to confirm the conclusions by breeding the type $\mathrm{C}$ backcross later. Note that the questionable effect of the cytoplasm detected in the $F_{1}$ is not confirmed by this backcross. It is of course possible that the effects of cytoplasm and $\mathrm{X}$ chromosome, which would be in opposite directions, are cancelling each other.

In the backcrosses to the high stock, all of which have been obtained (table 9), there is a significant effect attributable to rows and columns and their interaction (table 10). At first sight this indicates the action of both the second and $\mathrm{X}$ chromosomes (again, provided the cytoplasm is excluded). Arrangement of the means in the $2 \times 2$ table, however, urges some caution in this interpretation:

$$
\begin{array}{ll}
\text { A-26\% } & \text { C-20\% } \\
\text { D-30\% } & \text { B-19\% }
\end{array}
$$

It can be seen that the "column " effect (chromosome 2) is clear enough, A being considerably greater than $\mathrm{C}$, and $\mathrm{D}$ than $\mathrm{B}$, but that the "row " effect (X chromosome) and the interaction are almost entirely the result of the difference between $A$ and $D$. Unfortunately the A type backcross consists of only four males tested, and must therefore be considered unreliable; however B is only a little more reliable (eight males tested), and were B actually to have a recombination fraction of around 23 per cent (this is within the 95 per cent confidence limit of 23.33 per cent, unweighted), then the row and column effects would be real. 
TABLe 9

The backcross to the high stock: recombination rates in males

\begin{tabular}{|c|c|c|c|c|c|c|c|c|}
\hline \multirow[b]{2}{*}{$\begin{array}{l}\text { Type of } \\
\text { cross }\end{array}$} & \multirow[b]{2}{*}{$\begin{array}{l}\text { No. of } \\
\text { back- } \\
\text { crosses }\end{array}$} & \multirow[b]{2}{*}{$\begin{array}{l}\text { No. of } \\
\text { males } \\
\text { tested }(k)\end{array}$} & \multirow[b]{2}{*}{$\begin{array}{l}\text { No. of } \\
\text { offspring } \\
\text { scored }\end{array}$} & \multirow[b]{2}{*}{$\begin{array}{l}\text { No. of } \\
\text { recombi- } \\
\text { nants }\end{array}$} & \multicolumn{2}{|c|}{ Recombination rate } & \multirow[b]{2}{*}{$x^{2}$} & \multirow[b]{2}{*}{$\mathbf{P}$} \\
\hline & & & & & Weighted & $\begin{array}{c}\text { Un- } \\
\text { weighted }\end{array}$ & & \\
\hline $\begin{array}{l}\text { A } \\
\text { B } \\
\text { C } \\
\text { D }\end{array}$ & $\begin{array}{l}1 \\
1 \\
6 \\
2\end{array}$ & $\begin{array}{c}4 \\
8 \\
35 \\
14^{*}\end{array}$ & $\begin{array}{r}404 \\
537 \\
2571 \\
3016\end{array}$ & $\begin{array}{l}105 \\
102 \\
501 \\
895\end{array}$ & $\begin{array}{l}0.260 \\
0.190 \\
0.195 \\
0.297\end{array}$ & $\begin{array}{l}0.255 \\
0.179 \\
0.198 \\
0.297\end{array}$ & $\begin{array}{r}0 \cdot 07 \\
6 \cdot 42 \\
51 \cdot 37 \\
14 \cdot 86\end{array}$ & $\begin{array}{l}0.99 \\
0 \cdot 49 \\
0 \cdot 03 \\
0.46\end{array}$ \\
\hline Total & 10 & $61 \uparrow$ & 6528 & 1603 & 0.246 & $0.232 \ddagger$ & 153.52 & $O\left(10^{-8}\right)$ \\
\hline
\end{tabular}

Offspring of $p^{s} Y /++$ males mated to homozygous wild-type females (the males derived from $p^{s} \gamma /++$ females of the $F_{1}$ crossed to wild-type males of the high stock).

* Two of the males were mated each to two females; their broods have been scored separately for the unweighted mean and for the $\chi^{2}$ test, which consequently has 15 degrees of freedom.

$\uparrow$ Total $\chi^{2}$ has 62 degrees of freedom.

$\ddagger$ All four types of cross weighted equally.

\section{TABLE 10}

Analysis of $\chi^{2}$ for the backcross to the high stock

\begin{tabular}{|c|c|c|c|c|c|c|}
\hline \multirow{2}{*}{$\begin{array}{l}\text { Broods } \\
\text { combined }\end{array}$} & \multicolumn{2}{|c|}{ Overall } & \multicolumn{4}{|c|}{ Residual heterogeneity } \\
\hline & $\chi^{2}$ & df & Broods subtracted* & $\chi_{1}^{2}$ & $\mathbf{P}$ & Source \\
\hline$A+C$ & $58 \cdot 02$ & 38 & $A$ and $C$ & $6 \cdot 58$ & 0.01 & - \\
\hline$B+D$ & $46 \cdot 14$ & 23 & $\mathrm{~B}$ and $\mathrm{D}$ & $24 \cdot 86$ & $6 \cdot 1 \times 10^{-7}$ & - \\
\hline$A+D$ & 17.75 & 19 & $A$ and $D$ & $2 \cdot 83$ & 0.09 & - \\
\hline$B+C$ & 57.93 & 42 & $B$ and $C$ & $0 \cdot 13$ & 0.72 & - \\
\hline$A+B+C+D$ & 153.51 & 62 & $(A+C)$ and $(B+D)$ & 49.35 & $<10^{-9} \uparrow$ & $\mathrm{X}$ chromosome \\
\hline$A+B+C+D$ & $153 \cdot 51$ & 62 & $(A+D)$ and $(B+C)$ & $77 \cdot 83$ & $\ll 10^{-9 \dagger}$ & Chromosome 2 \\
\hline$A+B+C+D$ & $153 \cdot 51$ & 62 & $(\mathrm{~A}+\mathrm{B})$ and $(\mathrm{C}+\mathrm{D})$ & $5 \cdot 11$ & 0.02 & Interaction \\
\hline
\end{tabular}

* Values of $\chi^{2}$ and d.f. $(=k-1)$ are in table 9.

$\dagger$ One-tailed, provided cytoplasm has no effect.

$\ddagger$ One-tailed.

We can say that it is extremely likely that there is a recombination modifier carried in chromosome 2, the high allele being recessive (as the gene does not segregate in the backcross to low), and raising recombination by between 6 per cent and 11 per cent, and that it is possible, but by no means certain, that there is a similar gene in the $\mathrm{X}$ chromosome (high also recessive) increasing recombination by $1 \frac{1}{2}$ per cent to 4 per cent.

(c) The remaining autosomes. Each type of backcross is homogeneous for genes on the $\mathrm{X}$ and second chromosomes; the significantly greater than random variance (shown by $\chi^{2}$ ) within the larger backcrosses (tables 7 and 9 ) shows that further chromosomes are segregating. Among the high backcrosses $\mathrm{A}$ and $\mathrm{D}$ are too small to analyse, but as $\mathrm{B}$ and $\mathrm{C}$ are homogeneous (table 10) they can be combined into a single histogram (fig. $3 a$ ). This shows a rather marked antimode at a recombination fraction of 19 per cent, which divides the distribution almost exactly in a backcross ratio (21:22). As is shown by the shading in the histogram, all the larger replicates of the cross segregate on both sides of the antimode. Within each half of this distribution the crossover values are homogeneous (for the low and high modes respectively $\left.\chi_{20}^{2}=6.58, \quad P=0.99 ; \chi_{21}^{2}=11.62, \quad P=0.95\right)$ and have 


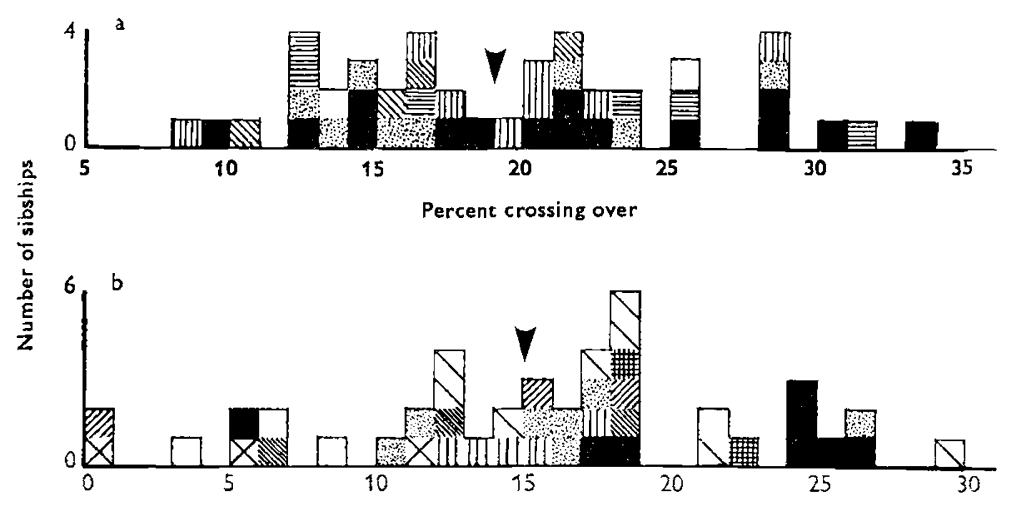

FIG. 3a.-Distribution of recombination fractions in the high backcrosses of types B and C. Identical shading indicates the male offspring of a single backcross mating. White indicates miscellaneous backcrosses represented by only one tested male each. Arrow is antimode.

FIG. 3b.-Distribution of recombination fractions in all the low backcrosses. Shading indicates replicate tests of males from the same backcross mating. White indicates miscellaneous backcrosses represented by only one tested male each. Arrow is dubious antimode.

variances which are as low as those of the parental stocks and $F_{1}(\chi / \sqrt{ } N=$ 0.07 and 0.08 ). Thus, although any number of chromosomes besides $X$ and 2 may be influencing recombination in this cross, the data are adequately explained by the segregation of one further autosome. The means of the two modes are respectively 0.15 and 0.23 (weighted). Thus if one autosome is involved, it is responsible for a difference of 8 per cent in the recombination fraction.

The backcrosses to low are harder to analyse; the combined distribution appears to be multimodal, with most replicates segregating in most of the modes (fig. $3 b$ ). The apparent antimode at 20 per cent divides the distribution $3: \mathrm{I}$, and leaves the low mode heterogeneous $\left(\chi_{31}^{2}=54 \cdot 67, \mathrm{P}=0.005\right)$. There is, it so happens, a poorly defined antimode at 15 per cent which divides the distribution into a backcross ratio (18:25), leaving two modes which are homogeneous and have a low variance (for the lower and upper modes respectively $\chi_{17}^{2}=22.37, \quad \mathrm{P}=0.17, \quad \chi / \sqrt{ } \mathcal{N}=0.1 \mathrm{I} ; \chi_{23}^{2}=28.25$, $\mathrm{P}=0.2 \mathrm{I}, \chi / \sqrt{ } \mathcal{N}=0.09)$. The means of the modes so defined are $0.1 \mathrm{I}$ and $0 \cdot 20$ (weighted). (Discrepancies in total numbers arise from including or excluding the intercross brood described on p. 279.) The difference is therefore almost the same as the similar difference in the high backcross. Thus this backcross can be explained in the same terms as the high backcrosses, by the segregation of one further autosome, low in this case being recessive, although there is no strong reason for preferring this explanation to a more complicated one involving several autosomes. .

If a single autosome is segregating in each backcross, then the question arises, is this a single autosome with an intermediate heterozygote, or two different autosomes with dominance in opposite directions? Unfortunately the $F_{2}$ (fig. 1) is too small and subject to too great an error variance to answer this. 


\section{Discussion}

\section{(i) Genetics of recombination control}

It is clear that the present difference of 23 per cent in recombination between Hasimoto's high and low selected lines is produced genically, and not by a large inversion. The analysis permits identification of the chromosomes involved, although not of the number of loci, as the chromosomes are transmitted intact through the females.

It is likely that most of the genetic factors influencing recombination in these experiments are in some way affecting the rate of crossing-over in the chromosomes. The alternative is that Hasimoto succeeded in selecting modifiers of viability which reduce the proportion of coupling or repulsion phenotypes in the offspring. But this is unlikely, as natural selection should have radically lowered the frequency of such genes in the dozen or more generations in which the stocks have been maintained under relaxed selection in the stock centre (it could be that the drop of 7 per cent in the high line between the attained value and that recorded here was due to just this). If there were such viability genes, they would segregate and very probably produce disturbed primary ratios in some types of cross; however, not only is there no overall disturbance of the primary ratios, but all classes of brood are homogeneous in the numbers of broods giving too good, adequate or poor fits to the $1: 1$ ratio (for a $14 \times 3$ table, $\chi_{26}^{2}=19 \cdot 1, \mathrm{P}=0 \cdot 87$ ). Viability modifiers are virtually excluded. Bombyx mori, and by implication the lepidoptera, with their rather unusual acentric chromosomes, joins the list of organisms (Drosophila, Schizosaccharomyces, Neurospora, Ascobolus, Phaseolus, Mus and Tribolium-Bombyx in fact joined this list 19 years ago) in which recombination has been shown to be under genetic control.

Four major classes of genes controlling recombination have been recognised in fungi (Catcheside, 1977). (1) Mutants altering the rate of recombination throughout the genome, frequently affecting other functions of cell division as well, and often lowering fertility (known also in Drosophila). (2) Repressor mutants (rec genes) affecting recombination in short lengths of chromosome elsewhere in the genome, frequently not linked to the rec mutant; it is supposed that these work through a recognition site or control gene (con) situated in the region where recombination is altered. (3) Recognition sites (cog genes) for the nicking of the DNA, affecting recombination in their own region. (4) Mutants reducing the degree of pairing at the site of chiasma formation ( $c v$ genes). The first two classes of mutant can control recombination at sites remote from their own; classes (3) and (4) will clearly map in the region in which recombination has been altered.

The present experiments have detected two effects attributable to the marked chromosome itself. The first is a small effect ( 5 per cent at the most), which requires further confirmation, due to an element in gametic disequilibrium with the marked segment. A factor in Drosophila, originally attributed to the cytoplasm (Kidwell, 1972a), may be due to a similar disequilibrium between a gene and the marked segment. It is not produced by a large inversion, and therefore could be a small inversion within the marked segment, or a $\operatorname{cog}$ or $c v$ type mutation in this region. Mutations of the $c v$ type, which repress recombination when heterozygous, are bound to be in gametic disequilibrium with the segment, but would segregate both in 
the high and in the low backcrosses. As no effect of chromosome 2 appears in the low backcross, a $c v$ type mutant is ruled out within the limits of statistical error. A $\operatorname{cog}$ mutant could be in disequilibrium with the marked segment, although there is no obvious reason why it should be; high recombination should be at least partly dominant, a prediction confirmed by the $\operatorname{cog}$ genes of Neurospora (see Catcheside, 1977), and again the lack of segregation in the low backcross, on the face of it, rules out a mutant of this kind. Although the whole effect could be spurious, it must be remembered that Kidwell (l.c.) may have found something similar in Drosophila.

A much larger and clearer effect of the selected, marked chromosome is one of between 6 and 11 per cent; as the high alleles are recessive, both $\operatorname{cog}$ and $c v$ mutants are ruled out. At least one other autosome has a similar effect ( 8 or 9 per cent), with high recessive, or at the most with an intermediate heterozygote, and there is at least one other autosome, and quite probably several more, with low recessive (identity with the previous autosome and hence an intermediate heterozygote, not being ruled out). There may be small effects from the $\mathrm{X}$ chromosome ( 4 per cent at the most, high recessive) and the cytoplasm. There is no way of knowing which of the remaining 26 autosomes may be involved, but what is clear is that recombination in chromosome 2 is controlled by several chromosomes, including chromosome 2 itself. Similarly in Drosophila recombination in the $\mathrm{X}$ chromosome is controlled by elements in all the large chromosomes, including the X (Chinnici, 1971b).

We do not yet know whether these multiple genes are specific controllers of recombination in chromosome 2 or whether they affect other chromosomes as well (the experiment planned to test this will take at least 5 years!); in Drosophila, Chinnici (1971b) found that some of the genes reducing recombination in the $\mathrm{X}$ chromosome had effects on other chromosomes, including the unexpected effect of increasing recombination in some segments. All the factors, including that in chromosome 2, which is shown not to be of the $\operatorname{cog}$ or $c v$ type, clearly involve action " at a distance " (the factor in chromosome 2 could be a mutation of the receptor con gene in such a system). It is likely that most of them are not general modifiers of recombination throughout the genome, as many of these would be expected to have major side effects on fertility, but are rather fine adjusters of recombination like the rec genes of Neurospora. The multigenic control of chromosome 2 is compatible with this suggestion, as in the length of chromosome spanned by the $p-\Upsilon$ segment (most of the known linkage map) it is quite conceivable that there are a number of recognition (con) genes each controlled by different rec genes scattered in different parts of the genome, and is also compatible with Chinnici's finding that the recombination modifiers affect several chromosomes, for the rec genes of Neurospora are each found to have more than one con gene, in various chromosomes, under their control. However, overall alterations in the rate of, say, DNA repair throughout the genome cannot be excluded.

In view of the large number of chromosomes (28) the fact that a gene (or genes) with a large effect on recombination has been found within the selected chromosome itself is rather significant. As the second chromosome was chosen solely because it had two dominant markers which are expressed at a convenient stage in the life cycle (the cocoon or imaginal markers on other chromosomes are extremely costly in leaves and labour), it suggests 
either that recombination modifiers are widespread within the genome and that in a randomly chosen chromosome we are likely to be able to select for a recombination modifier (it is of course much more readily selected in the marked chromosome than in any other), or that chromosomes tend to contain genes specifically controlling their own recombination rate, possibly mutants of the con loci.

\section{(ii) Supergenes in mimetic butterflies}

At first sight, the great lability of recombination in the silkworm lends support to the generally accepted theory (Clarke and Sheppard, 1971, 1972, and others) that the supergenes of mimetic butterflies like Papilio memnon, $P$. polytes and $P$. dardanus result from the tightening of linkage between originally widely-spaced loci. But paradoxically it now appears that these supergenes have a quite different origin.

Charlesworth and Charlesworth (1976) have shown that under the kind of number-dependent selection to which a Batesian mimic is subject, two loosely linked loci cannot both remain polymorphic; one or the other will go to fixation. Polymorphism occurs only for pairs of loci already tightly linked. Loosely linked loci cannot be subject to selection for tighter linkage, as both cannot be polymorphic at the same time.

Furthermore, most Muellerian mimics are monomorphic, and when they evolve a new pattern appear to progress rather rapidly to homozygosity for the new alleles, producing in the more rapidly evolving species a patchwork of monomorphic races (Turner, 1975, 1976; Turner et al., 1979). In most of them there must be quite insufficient time for recombination to be reduced to any significant extent and therefore, if this is the method by which supergenes evolve, there will be no supergenes in Muellerian mimics. Of course, as one cannot in the last analysis distinguish between a supergene and a series of alleles at a complex locus, it has been asserted that Muellerian mimics in the genera Heliconius and Zygaena do not exhibit supergenes (Clarke et al., 1968). As was pointed out (Turner, 1971) this conclusion was unsafe: the apparent three alleles at the $D$ locus of Heliconius melpomene look very like three of the possible four combinations of two alleles at two tightly linked loci, one affecting the forewing and the other the hindwing; the missing combination appears (with two of the others) in the closely related polymorphic species Heliconius timareta (Turner and Crane, 1962). Dryja (1959) had evidence that one of the loci in Zygaena ephialtes was a similar complex of two loci. Now we have found a similar supergene in Heliconius erato (Sheppard, Turner, Brown, Benson and Singer, in prep.): the loci producing red marks over the base of the wings, and converting the forewing band from red to yellow, are extremely tightly linked. There are several looser linkages in these butterflies, for instance in both $H$. melpomene and $H$. erato the yellow bar and white hindwing border of the West Ecuadorian races are linked (Emsley, 1965).

Supergenes in mimetic butterflies must therefore arise by the alternative mechanism, which is one of a class of mechanisms which may collectively be called "sieves" (Turner, 1977). A sieve is a selective system which, given a range of mutants of roughly equal selective value in relation to some component of the environment, gives preference to those with particular properties of dominance, sex limitation, linkage or other features of the genetic 
architecture. In the case of mimicry, an allele at a second locus can increase in frequency only if it is already rather tightly linked to an already polymorphic locus (Charlesworth and Charlesworth, 1976). In Batesian mimics the requirement for tight linkage is strict, because the polymorphism is balanced and long-lasting. In Muellerian mimics the first locus is polymorphic only for a brief period, and the nearer it is to fixation the more relaxed the restrictions on the linkage of the second locus become; once the first locus is monomorphic there is no restriction at all (Turner, 1977). Hence in Heliconius the supergenes never contain (as far as we can judge) more than two loci, compared with six in Papilio memnon, and other loci are loosely linked or independent.

But once a supergene has been formed by this mechanism, then linkage within it might be considerably increased by the kind of modifiers which have been shown to occur in Bombyx, although a considerable time would be needed, for as Charlesworth and Charlesworth (1976) show, the selection intensity in this range of recombination is very low.

\section{(iii) Why does the genome not congeal?}

Maynard Smith (1978) has pointed out that if natural selection favours reduced recombination over long periods, then the high recombination alleles found in natural populations will tend to be recessive. Some studies have confirmed this (Kidwell, 1972a, $b$; Dewees, 1975). In Bombyx, as in Chinnici's $(1971 a, b)$ studies of Drosophila, there is no overall dominance (the raised level in the low backcross suggesting a slight dominance of high genes under some circumstances). It may be that four millenia of artificial selection have radically changed the genetic architecture of the silkworm in this respect.

Although modifiers of recombination acting specifically on their own immediate region are known in fungi (Catcheside, 1977), neither in Bombyx nor in Drosophila (Chinnici, 1971b) have these been successfully selected; in Drosophila the genes involved appear to be of the rec type, and in Bombyx we have either rec genes or general modifiers of total genome recombination. In fact there appear to be considerable difficulties in both animals in stopping recombination in one chromosome segment, for as Nei (1969) pointed out, the absence of recombination in the heterogametic sex, seen in female Bombyx as in male Drosophila, probably arises from selection against recombination between the $\mathrm{X}$ and $\mathrm{Y}$ chromosomes. If modifiers specific to the sex chromosome are not readily available, the outcome will be the shutting off of recombination in the whole genome of one sex. Thus it seems likely that both Drosophila and lepidopterans (in all of which, so far as is known, chiasmata are absent in the female [e.g. Suomalainen, 1965; Suomalainen et al., 1973; Turner and Sheppard, 1975; Traut, 1977]), are rather short of specific modifiers of recombination, even the rec genes perhaps affecting several chromosomes at once. If this is true, then despite the genetic lability of recombination, it may be rather difficult for supergenes to evolve by the tightening of linkage between widely spaced, interacting loci.

If it should turn out that many of the recombination modifiers in eukaryotes are not specific to limited lengths of chromosome, but modify recombination generally throughout the genome, or at least in several chromosomes at once, then this, coupled with the sieving effect, might in 
part explain why the genome does not congeal despite the apparent plenty of recombination-reducing genes. Specific modifiers could, over a long period, congeal the whole genome in easy stages by condensing a few loci at a time into a supergene. However, if only general modifiers are available, then individual pairs of loci cannot be brought together in this way, and if there is a long delay before linkage between them is increased, then it is possible that one of them will be replaced by the substitution of an allele of roughly similar adaptive value at a locus more closely linked to the other locus, so considerably reducing the intensity of selection on the recombination fraction, which is now only acting to reduce still further a low level of crossing-over. As a considerable proportion of the gamete frequencies which a population can have for a set of loci must be such as to cause selection for increased recombination, general modifiers may at any one time be subject to selective pressures for increased and decreased recombination which are roughly equal. Although populations tend to approach equilibria with gamete frequencies such that selection favours decreased recombination, there may be at any one time enough pairs of loci in the genome that are out of equilibrium and subject to selection in the opposite sense, to put a considerable brake on the overall tightening of linkage throughout the genome. A similar braking effect will be produced by modifiers of the type found by Chinnici $(1971 b)$ which, while decreasing recombination in one part of the genome, increase it in other parts. In view of what we know about their mode of formation in mimetic butterflies, supergenes cannot necessarily be taken as evidence that natural selection is actually tending to make the genome congeal (see also Schaap, 1978).

\section{Conalusions}

The basis of the unusually large and fast response of the silkworm to selection for increased and reduced recombination is the control of recombination by several chromosomal genes, including one or more in the selected chromosome itself. As several chromosomes are involved (besides the marked one, at least one further autosome, probably two, and possibly three or more, as well as the X chromosome), action is "at a distance", and the genes appear to be either general modifiers of recombination, or something like the rec genes of Neurospora (Catcheside, 1977). In view of the fact that choice of a chromosome for selection is effectively random it may be that such recombination controlling genes are widely scattered in the genome.

To judge from this species, recombination fractions in lepidoptera might be readily altered by natural selection, which may therefore be most effective in tightening still further the linkage within existing supergenes. But other considerations show that the supergenes in mimetic butterflies are not formed initially by tightening the linkage between loosely linked genes, but by selecting alleles at loci that are already rather tightly linked. The existence of such supergenes is therefore not evidence in favour of the theory that natural selection makes the genome "congeal", and the mode of action of $r e c$ genes and of general modifiers of recombination, in altering recombination in several chromosomes at once (they have apparently been used in preference to specific local modifiers to stop recombination between the $\mathrm{X}$ and $\mathrm{Y}$ chromosomes of lepidoptera), suggests that these may put a considerable brake on the overall tightening of linkage in the genome. The 
variability of Bombyx mori for recombination controlling genes, shown by its rapid response to selection, suggests that at least this domesticated species has been subject to selection for intermediate levels of crossing-over or to selection both for increased and decreased recombination in different parts of the genome.

Acknowledgments.-The progress of this work has been dependent on the considerable skills of Mr Mart Koello, who adapted the Japanese techniques of silkworm rearing to our needs, and oversaw the rearing of the broods; he is co-author of section 3. Much additional help was provided by Dr Charles Mitter, Mr Craig Sargent and Ms Melody Wolstoff. To all these people I am extremely grateful. I am much indebted to Professor Hiroshi Doira who provided several batches of the high and low stocks from Kyushu University. The research was supported by grant 5 ROl GM 20702 from the National Institutes of Health.

\section{REFERENCES}

ABDUllah, N. F., AND CHARLESWORTH, B. 1974. Selection for reduced crossing over in Drosophila melanogaster. Genetics, 76, 447-451.

ACton, A. B. 1961. An unsuccessful attempt to reduce recombination by selection. Amer. Natur., 95, 119-120.

ALlARD, R. W. 1963. Evidence for genetic restriction of recombination in the lima bean. Genetics, 48, 1389-1395.

AYUZAWA, Ch., SEKIDO, I., YamakaWA, K., SAKUKAI, U., KURATA, W., YAGINUMA, Y., AND TOKoro, Y. 1972. Handbook of Silkworm Rearing. Agricultural Technique Manual. Fuji Publishing Co. Ltd., Tokyo.

DE BOER, R., AND VAN DER HOEVEN, F. A. 1977. Son-sire regression based on heritability estimates of chiasma frequency, using $\mathrm{T} 7 \mathrm{OH}$ mouse translocation heterozygotes, and the relation between univalence, chiasma frequency and sperm production. Heredity, $39,335-343$.

CAtcheside, D. G. 1977. The Genetics of Recombination. Arnold, London.

CHARLESWORTH, B., AND CHARLESWORTH, D. 1976. Theoretical genetics of Batesian mimicry. II. Evolution of supergenes. F. Theor. Biol., 55, 305-324.

CHIkushi, H. 1972. Genes and Genetical Stocks of the Silkworm (Studies of Stock Culture in Biological Field No. 1). Keigaku, Tokyo.

CHINNICI, J. P. 1971a. Modification of recombination frequency in Drosophila. I. Selection for increased and decreased crossing over. Genetics, 69, 71-83.

ChINNICI, J. P. 1971b. Modification of recombination frequency in Drosophila. II. The polygenic control of crossing over. Genetics, 69, 85-96.

Clarke, C. A., AND SHEPPARD, P. M. 1971. Further studies on the genetics of the mimetic butterfly Papilio memnon L. Phil. Trans. Roy. Soc. London B, 263, 35-70.

ClARKE, C. A., AND SHEPPARD, P. M. 1972. The genetics of the mimetic butterfly Papilio polytes L. Phil. Trans. Roy. Soc. London B, 263, 431-458.

GLARKE, C. A., AND SHEPPARD, P. M. 1977. A new tailed female form of Papilio memnon L. and its probable genetic control. Syst. Entomol., 2, 17-19.

CLARKE, C. A., SHEPPARD, P. M., AND THORNTON, I. W. B. 1968. The genetics of the mimetic butterfly Papilio memnon L. Phil. Trans. Roy. Soc. London B, 254, 37-89.

DEWEES, A. A. 1975. Genetic modification of recombination rate in Tribolium castaneum. Genetics, 81, 537-552.

DRYJA, A. 1959. Badania nad polimorfizmem Kraśnika Zmiennego (Zygaena ephialtes L.). (Genetical investigation on the polymorphism of Zygaena ephialtes L.). Panstwowe Wydawnictwo Naukowe, Warszawa, pp. $401+$ folder of 12 plates and tables.

EMSLEY, M. G. 1965. The geographical distribution of the color-pattern components of Heliconius erato and Heliconius melpomene with genetical evidence for the systematic relationship between the two species. Zoologica (New York), 49, 245-286.

FISHER, R. A. 1930. The Genetical Theory of Natural Selection. Clarendon Press, Oxford. hasimoto, H. 1960. Selection of crossover value between Striped and Yellow in the silkworm. 11eme Conference Technique Sericicole Internationale, Murcie (Espagne), 365-367.

KIDWELl, M. G. 1972a. Genetic change of recombination value in Drosophila melanogaster. I. Artificial selection for high and low recombination and some properties of recombination-modifying genes. Genetics, 70, 419-432. 
KIDWELL, M. G. 1972b. Genetic change of recombination value in Drosophila melanogaster. II. Simulated natural selection. Genetics, 70, 433-443.

MAYNARD SMITH, J. 1977. Why the genome does not congeal. Nature, 268, 693-696.

MAYNARD SMTTH, J. 1978. The Evolution of Sex. Cambridge University Press, London.

NEI, M. 1969. Linkage modification and sex difference in recombination. Genetics, 63, 681-699.

PARSONs, P. A. 1958. Selection for increased recombination in Drosophila melanogaster. Amer. Natur., 92, 255-256.

SCHAPP, T. 1978. Why should the genome congeal? Nature, 276, 535-536.

sHAw, D. D. 1972. Genetic and environmental components of chiasma control. II. The response to selection in Schistocerca. Chromosoma, 37, 297-308.

SHEPPARD, P. M. 1975. Natural Selection and Heredity, fourth edition. Hutchinson, London. STURTEVANT, A. H. 1915. No crossing over in the female of the silkworm moth. Amer. Natur., 49, 42-44.

suomalainen, E. 1965. On the chromosomes of the Geometrid moth genus Cidaria. Chromosoma (Berlin), 16, 166-184.

suomalatnen, E., COOK, L. M., AND TURNER, J. R. G. 1973. Achiasmatic oogenesis in the heliconiine butterflies. Hereditas, 74, 302-304.

TRAUT, w. 1977. A study of recombination, formation of chiasmata and synaptonemal complexes in female and male meiosis of Ephestia kuehniella (Lepidoptera). Genetica, 47, 135-142.

TURNER, J. R. G. 1971. Studies of Müllerian mimicry and its evolution in burnet moths and heliconid butterflies. In Ecological Genetics and Evolution, ed. E. R. Creed, pp. 224-260. Blackwell Scientific Publications, Oxford.

TURNer, J. R. G. 1975. A tale of two butterflies. Natural History, 84 (2), 28-37.

TURNER, J. R. G. 1976. Muellerian mimicry: classical "beanbag" evolution, and the role of ecological islands in adaptive race formation. In Population Genetics and Ecology, ed. S. Karlin and E. Nevo, pp. 185-218. Academic Press, New York and London.

TURNER, J. R. G. 1977. Butterfly mimicry: the genetical evolution of an adaptation. Evol. Biol., 10, 163-206.

TURNER, J. R. G., AND CRANE, J. 1962. The genetics of some polymorphic forms of the butterflies Heliconius melpomene Linnaeus and $H$. erato Linnaeus. I. Major genes. Zoologica (New York), 47, 141-152.

TURNER, J. R. G., Johnson, M. s., AND EANES, w. F. 1979. Contrasted modes of evolution in the same genome: allozymes and adaptive change in Heliconius. Proc. Natl. Acad. Sci. USA, 76, 1924-1928.

TURNER, J. R. G., AND SHEPPARD, P. M. 1975. Absence of crossing-over in female butterflies (Heliconius). Heredity, 34, 265-269. 